\title{
PREOCUPAÇÕES AO LONGO DA CARREIRA DOCENTE: ESTUDOS DE CASO COM PROFESSORES DE EDUCAÇÃO FÍSICA DO MAGISTÉRIO PÚBLICO ESTADUAL
}

\author{
MS. ALEXANDRA FOLLE \\ Mestre em Educação Física pelo Centro de Desportos da Universidade \\ Federal de Santa Catarina (CDS/UFSC) \\ Professora do Centro de Ciências da Saúde e do Esporte da Universidade do \\ Estado de Santa Catarina (CEFID/UDESC) \\ Laboratório de Pedagogia do Esporte (LAPE/CDS/UFSC) \\ (Florianópolis - Santa Catarina - Brasil) \\ E-mail: afolle_12@hotmail.com
}

\author{
DR. JUAREZ VIEIRA DO NASCIMENTO \\ Doutor em Ciências do Esporte pela Faculdade de Desporto da \\ Universidade do Porto (FADE/UP) \\ Professor Associado III do Centro de Desportos da Universidade \\ Federal de Santa Catarina (CDS/USFC) \\ Laboratório de Pedagogia do Esporte (LAPE/CDS/UFSC) \\ (Florianópolis - Santa Catarina - Brasil) \\ E-mail: juarezvn@cds.ufsc.br
}

\begin{abstract}
RESUMO
O objetivo do estudo foi analisar as preocupações de professores de Educação Física. Participaram do estudo quatro professores efetivos e com mais de 25 anos de atuação no magistério público estadual de Santa Catarina. Entrevistas semiestruturadas foram realizadas, e a técnica de análise de conteúdo foi utilizada na análise das informações. Os resultados revelaram alterações importantes nas percepções de preocupações ao longo da carreira docente. Os professores iniciaram na profissão preocupados com as condições de trabalho ofertadas, pautando-se posteriormente na ação didática e nas propostas governamentais para a escola pública. Nos ciclos finais de vida docente destacaram-se as preocupações com os problemas sociais a que os alunos são expostos.
\end{abstract}

PALAVRAS-CHAVE: Docentes; preocupações; escolas públicas; educação fisica. 
A carreira docente vem sendo analisada sob diferentes perspectivas, principalmente no que concerne ao desenvolvimento profissional dos professores, demonstrando um avanço no interesse da comunidade acadêmica sobre o trabalho e a vida dos educadores (OSLER, 1997). Além de evidenciarem determinados aspectos que caracterizam os ciclos de vida docente, algumas recomendações são apresentadas para a melhoria das condições de vida no trabalho docente (BOTH; NASCIMENTO; BORGATTO, 2008; FARIAS et al., 2008a; FOLLE et al., 2008; LEMOS; NASCIMENTO; BORGATTO, 2007).

As investigações que abordam as preocupações pedagógicas (SHIGUNOV; FARIAS; NASCIMENTO, 2002), as competências profissionais (NASCIMENTO; GRAÇA, 1998) e os momentos marcantes da carreira docente (FOLLE et al., 2009; FOLLE; NASCIMENTO, 2009; SHIGUNOV; FARIAS; NASCIMENTO, 2002) são ainda escassas, necessitando de maiores aprofundamentos para a compreensão de possíveis mudanças ocorridas na percepção dos professores com o avanço nas fases que caracterizam o desenvolvimento profissional docente (BARONE et al., 1996; HUBERMAN, 2000; NASCIMENTO; GRAÇA, 1998; STEFY et al., 2000; STROOT, 1996).

No que se refere às preocupações pedagógicas, encontram-se alguns estudos realizados nas décadas de 1980 e 1990, nomeadamente com estudantes de cursos de formação de professores em situação de estágio (MATOS et al., I99 I ; MCBRIDE, 1984; OLSEN; HEYSE, 1990; WENDT; BAIN; JACKSON, I98I; ZIELINSKI; PRESTON, 1992) e algumas investigações com educadores em início de carreira ou que se encontram em fases mais avançadas do percurso docente (HOLLY, 2000; MARSO; PIGGE, 1994).

No Brasil, somente nos últimos anos iniciaram-se as primeiras investigações em torno das preocupações pedagógicas de estudantes universitários (FARIAS et al., 2008b), bem como de professores inseridos no contexto universitário e escolar (HOPF; CANFIELD, 200 I; SHIGUNOV; FARIAS; NASCIMENTO, 2002), demonstrando o estágio inicial do entendimento da interferência da experiência profissional na percepção dos problemas vivenciados no ambiente educacional.

$\mathrm{Na}$ literatura consultada, especialmente entre os estudos internacionais, percebe-se a ênfase atribuída pelos investigadores ao modelo de preocupações com o ensino proposto por Fuller ( 1969 ), o qual destaca como anseios de estudantes universitários e de professores inseridos no contexto escolar as preocupações 'consigo próprio' (self), com a 'tarefa' (task) e com o 'impacto' (impact) (FULLER; CASE, 1969; MARSO; PIGGE, 1994; MCBRIDE, I984; OLSEN; HEYSE, I990; WENDT; 
BAIN; JACKSON, | 98I). Neste caso, as preocupações da dimensão 'consigo próprio' compreendem aspectos relacionados com a 'sobrevivência' na condição de professor. A dimensão 'tarefa' se relaciona com as situações de ensino, e a dimensão 'impacto' se refere aos problemas sociais dos alunos (FULLER, 1969; MATOS et al., 1991; MCBRIDE, 1984; SHIGUNOV; FARIAS; NASCIMENTO, 2002).

Diante da escassez de publicações nacionais sobre as preocupações de professores com o ensino e a necessidade de aprofundamento na apreciação do desenvolvimento profissional docente, o objetivo deste estudo foi analisar as preocupações de professores de Educação Física do magistério público estadual de Santa Catarina.

\section{PROCEDIMENTOS METODOLÓGICOS}

\section{CARACTERIZAÇÃO DO ESTUDO}

O presente estudo se caracteriza como estudo de casos múltiplos (MOLINA, 2004), com abordagem qualitativa das informações. A maioria dos estudos qualitativos é conduzida com amostras pequenas, tendo como objetivo captar a interpretação que determinada pessoa faz da sua própria vida (BOGDAN; BIKLEN, 1994).

\section{PARTICIPANTES DO ESTUDO}

As preocupações pedagógicas de quatro professores de Educação Física do magistério público estadual da cidade de Florianópolis (SC) foram investigadas, levando-se em consideração os seguintes critérios para inclusão e exclusão dos participantes na investigação:

a) Critérios de inclusão: ser professor efetivo de Educação Física no magistério público estadual; ter mais de vinte e cinco anos de intervenção profissional no magistério público estadual; atuar em sala de aula;

b) Critérios de exclusão: estar aposentado; exercer cargos administrativos na escola ou na Secretaria Estadual de Educação; estar afastado da escola por qualquer tipo de licença.

Os professores participantes do estudo apresentam as seguintes características:

- Professor A: possui 28 anos de intervenção profissional no magistério público estadual, assumiu cargo comissionado de diretor de escola de 1986 a 1987 e concilia suas atividades docentes com o ensino particular há 26 anos; 
- Professor B: possui 32 anos de atuação em escolas estaduais, assumiu cargo de diretor de escola eleito, nos períodos de 1991 a 1995 e de 1999 a 2003, conciliando as atividades no magistério com a arbitragem de modalidade esportiva estadual, nacional e internacional;

- Professora C: possui 29 anos de carreira no magistério estadual, assumindo em sua trajetória os cargos comissionados de diretora, secretária e assistente durante 15 anos;

- Professora D: possui 27 anos de atuação no ensino público estadual, trabalhou no início da carreira docente na rede municipal durante seis anos, assumiu cargo de diretora de escola eleita de 1991 a 1993, tendo como maior suporte de sua intervenção as atividades rítmicas e expressivas.

\section{INSTRUMENTOS E COLETA DAS INFORMAÇÕES}

Na coleta das informações foram utilizadas: a) entrevistas semiestruturadas com os professores de Educação Física; b) entrevistas semiestruturadas com três colegas de trabalho (um representante da esfera administrativa, um representante da esfera pedagógica e um representante do corpo docente) de cada professor investigado. Na seleção dos colegas de trabalho, foi solicitado aos professores sujeitos da pesquisa que indicassem um representante de cada uma dessas esferas para contribuírem com informações sobre sua trajetória docente.

O presente estudo foi aprovado pelo Comitê de Ética em Pesquisa com Seres Humanos da Universidade Federal de Santa Catarina (n 029/08). Após a sua aprovação, foi realizado o primeiro contato por telefone com as secretarias das escolas em que os professores com mais de vinte e cinco anos de intervenção profissional atuavam (informação disponibilizada pelo setor de Recursos Humanos da Gerência de Educação), para levantar dados necessários para inclusão e exclusão dos professores no estudo. A seleção final, a partir dos critérios estabelecidos, foi realizada por meio de contato pessoal para explicar os objetivos e os procedimentos do estudo, além da solicitação de assinatura do Termo de Consentimento Livre e Esclarecido.

Inicialmente foram entrevistados os professores de Educação Física e, em seguida, os colegas de trabalho indicados pelos investigados, de acordo com a disponibilidade de cada um. Todas as entrevistas foram realizadas individualmente, gravadas e transcritas na íntegra para facilitar o processo de análise dos dados e enviadas aos professores e colegas de trabalho (para alterarem e/ou confirmarem 
as informaç̧̃̃es contidas na transcrição), como processo de validação das descrições de seu conteúdo.

\section{ANÁLISE DAS INFORMAÇÕES}

As informações foram analisadas por meio da técnica de análise de conteúdo. A análise por meio dessa técnica funciona por operações de desmembramento do texto em unidades de significado, em categorias e segundo reagrupamentos analógicos (BARDIN, 1977). A validação interpretativa das categorias de análise encontradas no presente estudo foi realizada por dois professores com longa experiência investigativa em Educação Física, os quais acumulam anos de intervenção no magistério superior e publicações sobre a temática em capítulos de livros e em artigos de periódicos.

\section{RESULTADOS E DISCUSSÃO}

\section{O INÍCIO DA CARREIRA DOCENTE: A PREOCUPAÇÃO COM AS SITUAÇÕES DE ENSINO}

As preocupações relatadas por professores iniciantes estão geralmente associadas à responsabilidade por tornar-se professor e por assumir tarefas não desempenhadas em outros momentos (SHIGUNOV; FARIAS; NASCIMENTO, 2002). A distância entre a fundamentação teórica obtida durante o curso de formação inicial e a realidade educacional, bem como a multiplicidade de papéis que estão reservados aos educadores, desde o primeiro dia de sua intervenção, transformam a etapa de iniciação profissional em um contexto propício ao aparecimento de dilemas (SILVA, 1997).

A fase de entrada na carreira docente é frequentemente marcada pelo sentimento de choque com a realidade educacional, além da percepção de insegurança, de medo e de necessidade de sobrevivência na profissão (FOLLE et al., 2009; HUBERMAN, 2000; STEFY et al., 2000). Para tanto, as preocupações sentidas nesse momento remetem às preocupações 'consigo próprio' e com os conteúdos e não com os alunos (HOPF; CANFIELD, 200 I).

De modo contrário ao apontado na literatura consultada, os professores participantes do estudo revelaram que as preocupações 'consigo próprio' foram pouco marcantes no momento de ingresso no mercado de trabalho. Apenas os professores $B$ e $D$ relataram que experimentaram sentimentos de insegurança com relação à efetividade e à aceitação do trabalho que seria desenvolvido, além 
da percepção de não se sentirem preparados e com subsídios suficientes para desempenharem suas funções.

No início você não tem muito subsídio. Na parte pedagógica é só aquela coisa básica. Então você está preocupado em se interar da parte pedagógica da escola, procura saber como a escola trabalha nesse sentido (PROFESSOR B).

[...] foi bastante difícil porque eu não era uma pessoa falante, eu era tímida demais, falava muito pouco, era muito dificil eu passar um conceito, isso foi muito complicado para mim (PROFESSORA D).

Neste sentido, destaca-se que as preocupações no momento de entrada da carreira levaram estes professores a se questionarem sobre as suas competências e habilidades profissionais, as quais são importantes para proporcionar, nesta fase do desenvolvimento profissional docente, maior tranquilidade e adaptação do professor à vida escolar (SHIGUNOV; FARIAS; NASCIMENTO, 2002).

Os maiores dilemas do início da carreira docente dos entrevistados pautaramse em situações referentes ao 'impacto' de suas ações na vida dos estudantes e à 'tarefa' de ensinar, principalmente, no que tange à estrutura que era oferecida pelas escolas públicas para o desenvolvimento das ações pedagógicas na época.

$O$ professor $B$ destacou que, naquele momento, sua inquietação estava direcionada em como trabalhar com alunos de faixas etárias, níveis de desenvolvimento e crescimento físico diferenciados em uma mesma turma, bem como em desvendar como motivar em suas aulas crianças e adolescentes que repetiam muitos anos a mesma série. Por sua vez, as professoras C e D declararam que, ao se efetivarem no magistério público estadual, vivenciaram uma frustração muito grande com a estrutura proporcionada pelas escolas para que elas realizassem o trabalho por elas almejado.

Eu entrei preocupada mesmo com duas coisas: 'eu vou ter material?', 'eu vou ter espaço físico para trabalhar?' (PROFESSORA C).

Não tinha quadra, não tinham bolas. Eu pedi para a direção me mostrar o material, tinha pouquíssimo material, perguntei: 'só isso?'. Riram da minha cara, isso foi muito frustrante (PROFESSORA D).

No início da carreira também foram observadas preocupações com o 'impacto' das aulas de Educação Física no desenvolvimento e na aprendizagem dos alunos, as quais se pautaram na intenção de promover uma formação mais cidadã a cada educando, como pode ser observado na narrativa de um dos docentes investigados:

[...] tentar ajudá-los na formação, na formação de um caráter, para sair 'um cara gente boa', não apenas um atleta, mas um cidadão, um cara de bem (PROFESSOR A). 
Nesta perspectiva, enfatiza-se que os professores, apesar de vivenciarem o sentimento de "choque com a realidade" de escolas públicas, devido à ausência de uma infraestrutura adequada ao desenvolvimento do trabalho pedagógico, refletido nas narrativas de insatisfação com as condições materiais e de espaços adequados, não deixaram de se preocupar com as questões sociais que afetam o cotidiano dos alunos e sua formação na condição de cidadãos.

Estudos realizados com estudantes universitários em situação de estágio apresentaram resultados diferentes dos encontrados nessa investigação. Nessas pesquisas, observou-se o predomínio de preocupações com o domínio relativo ao 'impacto' e menor ansiedade com a 'tarefa' de ensinar (MARSO; PIGGE, 1994; FARIAS et al., 2008b; MATOS et al., 199I; WENDT; BAIN; JACKSON, 198I; ZIELINSKI; PRESTON, 1992).

As preocupações no momento de ingresso na profissão de professores de Educação Física brasileiros também se relacionaram mais com o 'impacto' e 'consigo próprio' do que com a 'tarefa' (SHIGUNOV; FARIAS; NASCIMENTO, 2002). Educadores americanos, investigados por Fuller e Case (1969), reforçam que pelo motivo de nunca terem entrado em uma sala de aula para ensinar, apresentaram-se pouco preocupados com o ensino como um todo.

As diferenças encontradas entre os resultados obtidos nessa investigação e os demais estudos mencionados podem estar associadas ao instrumento utilizado na coleta das informações e do número de professores participantes. Enquanto a maioria dos estudos mencionados utilizou um questionário com perguntas fechadas, a presente investigação baseou-se em entrevistas semiestruturadas.

Outro aspecto a destacar é que a maioria das pesquisas foi realizada com professores de outras áreas disciplinares e não com professores de Educação Física. No caso específico da docência em Educação Física, faz-se necessário enfatizar a peculiaridade dos materiais e espaços disponibilizados para o desenvolvimento das aulas, em especial nas escolas da rede pública de ensino na realidade brasileira, as quais em muitos casos não oferecem um ambiente propício aos professores para ministrarem as atividades planejadas. Esse fato pode ter sido responsável pela maior presença de preocupações com a 'tarefa' no início da vida profissional visualizada nessa investigação.

\section{O AVANÇO NA CARREIRA DOCENTE: A ANSIEDADE EM TORNO DAS SITUAÇÕES DE ENSINO INTENSIFICADA}

As preocupações de professores mais experientes parecem se concentrar na diversidade de atividades a serem desenvolvidas, bem como nas questões relativas ao conteúdo e ao material escasso nas escolas (SHIGUNOV; FARIAS; NASCIMENTO, 
2002). Os depoimentos dos professores de Educação Física se aproximaram dessa afirmação, haja vista as preocupações com as tarefas a serem executadas no ambiente escolar se intensificaram com a experiência profissional. Além disso, as preocupações com o 'impacto' tiveram uma diminuição (retornando somente no momento em que os professores se preparavam para abandonar o ensino) e as preocupações 'consigo próprio' foram suprimidas com o avanço na carreira.

[...] antigamente a gente trabalhava muito no improviso, não tínhamos material nem quadra para trabalhar, trabalhávamos no improviso [...] então se você quisesse trabalhar, se você quisesse desenvolver um trabalho, dava para desenvolver, mas não era um trabalho tão gostoso, tão legal, tão gratificante quanto você ter uma quadra, uma coisa gostosa de trabalhar (PROFESSOR B).

As evidências encontradas na investigação revelaram que, após os primeiros contatos com o ato educativo e com a atuação direta no dia a dia com os alunos, os professores de Educação Física se mantiveram apreensivos com a 'tarefa' de ensinar. Contudo, passaram de uma inquietação com os materiais e os espaços adequados para a prática de atividades físicas e esportivas para uma ansiedade em torno da ação didática e das propostas governamentais para o ensino público.

Nesta perspectiva, a partir das experiências adquiridas no contexto escolar público, os professores investigados autopercepcionam que as preocupações com sua sobrevivência na escola, sentidas no momento de ingresso no mercado de trabalho, diminuíram em função do aumento das preocupações com a tarefa.

Enquanto os professores B e D começaram a se preocupar com as políticas educacionais e as mudanças constantes nas metas e na legislação escolar, as quais não proporcionaram mudanças concretas na ação didática dos educadores, o professor A manteve e intensificou sua preocupação de levar seus alunos a gostarem da prática de atividades físicas e esportivas durante toda a sua intervenção profissional.

A minha preocupação é, foi e sempre será a de levar o aluno a gostar da Educação Física, gostar de brincar, gostar de se recrear, gostar de praticar algum esporte, de algum lazer. Por quê? Porque ele gostando, ele se entrosando com os outros, ele irá consequentemente se beneficiar em termos de saúde (PROFESSOR A).

A professora $D$ foi a que percebeu maior alteração nas suas inquietações com o aumento da experiência docente. Na medida em que conheceu melhor a realidade das escolas públicas, ela deixou de lado as preocupações com a sua própria sobrevivência na condição de docente para analisar e tentar contribuir na solução de problemas familiares e sociais. 
Comecei a olhar mais o lado humano, a realidade do educando [...] Eu andei na comunidade e conheci a realidade deles, onde eles viviam, os barracos, as famílias. Muitos filhos de alcoólatras, drogados ou pessoas depressivas, desempregados, famílias que às vezes são sustentadas pela avó com vários netos, pai que tem problema no trabalho, separados, muitos problemas realmente (PROFESSORA D).

As informações disponibilizadas pela professora $\mathrm{D}$ reforçam a constatação de que com o aumento no tempo de intervenção profissional no ensino, os professores tendem a apresentar maior preocupação com o 'impacto' de suas ações docentes sobre os educandos (MARSO; PIGGE, 1994). De modo similar, os professores de Educação Física brasileiros que se encontravam na fase de diversificação profissional (mais de sete anos de docência), participantes do estudo de Shigunov, Farias e Nascimento (2002), relataram a insegurança com o 'impacto' e com a 'tarefa', sendo pouco enfatizada a preocupação 'consigo próprio'. Com relação ao domínio 'impacto', tais educadores se revelaram centrados em questões sociais, como o uso constante de drogas, o relacionamento entre os alunos e a falta de motivação demonstrada durante as aulas.

A mudança no domínio das preocupações sobre o ensino de estudantes estagiários após um período de atuação em sala de aula também foi observada em estudo com professores americanos (OLSEN; HEYSE, 1990). Ao mesmo tempo em que adquiriram maior experiência, também demonstraram um declínio de preocupações 'consigo próprio' e com a 'tarefa', aumentando o nível de ansiedade com o 'impacto'.

\section{O MOMENTO DE RUPTURA COM A PROFISSÃO: A INQUIETAÇÃO COM OS PROBLEMAS SOCIAIS DOS ALUNOS}

$\mathrm{Na}$ fase final da carreira docente encontram-se professores com vasta bagagem e conhecimentos produzidos durante seu percurso em escolas públicas, os quais se sentem mais seguros em relação ao trabalho que desenvolvem e menos preocupados com a avaliação dos pares (SHIGUNOV; FARIAS; NASCIMENTO, 2002). De fato, os professores de Educação Física com mais de vinte e cinco anos de intervenção profissional no magistério estadual expressaram suas preocupações com o momento atual em que se encontram em relação ao sistema educacional, não enfatizando circunstâncias referentes à sobrevivência na profissão, tampouco à insegurança ou à falta de subsídios pedagógicos.

Nessa fase de suas carreiras, período em que aguardam ansiosos pela aposentadoria, suas preocupações estão fortemente ligadas ao 'impacto' das suas ações e da realidade social vivenciadas por seus alunos. O reforço do ensino público na 
exclusão social, do aumento da violência e das causas que levam os alunos a se desinteressarem pela Educação Física e demais disciplinas, entre outros aspectos, se intensificou como inquietação de educadores que já contribuíram durante anos com a educação pública e sentem os problemas sociais se agravarem. Tais sentimentos podem ser observados em suas narrativas:

Está mais difícil hoje em dia administrar todas essas coisas, questões sociais que tem por aí e estouram todas na escola, é a gente quem tem que administrar. Então realmente hoje em dia está bem mais complicado de trabalhar numa escola pública, com qualquer matéria, não é só Educação Física (PROFESSORA C).

Minha preocupação hoje é que a nossa clientela, do ensino público, não tem lugar na sociedade. São os excluídos e não irão ter emprego. O sistema mantém isso, e eu gostaria de ajudar a mudar esse sistema. Eu tenho uma grande preocupação com isso, estamos só reproduzindo aquilo que já está ali, estamos mantendo o sistema, e isso é muito frustrante (PROFESSORA D).

Professores brasileiros na fase final do percurso profissional também se mostraram pouco preocupados com o fato de serem observados, com a orientação pedagógica adotada e com o desempenho correto de sua função. Na medida em que as preocupações 'consigo próprio' diminuíram em função da 'tarefa', estas, com o avanço na carreira, diminuíram em função das preocupações com o 'impacto' (SHIGUNOV; FARIAS; NASCIMENTO, 2002).

Os quatro professores de Educação Física, participantes deste estudo, revelaram que sairão da escola angustiados com a situação social em que vivem seus alunos. Nesse sentido, destacaram que enquanto puderem contribuir com a educação, almejam auxiliar na melhoria do convívio e da inserção social, na conscientização com relação ao uso de drogas, bem como na promoção de mudanças na sociedade para a melhoria da escola pública.

Hoje a preocupação é maior na falta de interesse dos alunos, na evasão dos alunos, que é muito grande e, principalmente, na parte disciplinar. A parte de violência dentro da escola, essa daí está bem explícita, ela está bem concretizada, como eu não tive no início da carreira (PROFESSOR B).

Relatos semelhantes foram apresentados pela diretora da escola da professora C e pela orientadora educacional da escola da professora $\mathrm{D}$, as quais destacaram as inquietações das docentes de Educação Física com as relações pessoais e as situações sociais a que os alunos são expostos fora da escola e que acabam por influenciar no estímulo à aprendizagem. 
Uma das preocupações é com a relação pessoal do aluno, com certas situações que eles vivem. Ela procura ficar sabendo de várias coisas e se ela percebe que isso vem em prejuízo ao estímulo do aluno na escola, na sala de aula, na aprendizagem, ela busca estabelecer uma relação de diálogo com ele [...] (DIRETORA C).

Ela demonstra bastante preocupação com os alunos [...] porque o social nosso é muito forte, a comunidade é muito carente. Ela sempre traz para nós problemas graves de alunos, ela é uma das primeiras a descobrir se uma aluna está grávida, às vezes até pelas atividades que ela desenvolve. Alunos que estão indo para o vício, ela também percebe logo e já dá um toque (ORIENTADORA EDUCACIONAL D).

O professor A, além de manter seu interesse em levar os alunos a gostarem e se beneficiarem com a prática esportiva, nesse momento demonstra grande frustração com o aumento da violência e do desinteresse dos alunos na escola. A orientadora educacional da instituição escolar, na qual esse docente atua, confirmou a ansiedade deste educador em contribuir com uma formação mais cidadã dos seus alunos, como pode ser observado em sua narrativa:

[...] é um tipo de professor paizão, ele se preocupa com o aluno na íntegra, com o desempenho na escola, nas outras disciplinas, não só na dele. Ele senta e conversa com os alunos de igual pra igual. [...] quando ele vê que as atitudes na vida, fora da escola não estão sendo as melhores [...] ele se sente bem à vontade para interferir, para chamar atenção, para orientar, para conversar [...]. Ele é preocupado com o aluno como um todo, em todos os aspectos, como um ser humano completo [...] (ORIENTADORA EDUCACIONAL A).

Os depoimentos dos colegas de trabalho dos professores A e B reforçaram a manifestação de preocupações destes docentes com relação ao aumento da violência, da agressividade e do desinteresse dos educandos.

[...] trabalha assim, preocupado com droga, violência, sexualidade [...] lá na quadra ele vê muita coisa (DIRETORA A).

[...] aprendizagem, disciplina, como eles têm mudado o comportamento [...]. Como tem piorado a Educação dos alunos. [...] essa é a preocupação dele, de todos nós (ADMINISTRADORA B).

As evidências encontradas no presente estudo, com relação às preocupações atuais de professores que se encontram no final da carreira docente, evidenciam a apreensão com o aumento da violência e dos problemas familiares, bem como da falta de segurança no ambiente escolar. Além disso, configuram uma tendência atual de preocupações com os problemas sociais oriundos do cotidiano de vida que os alunos de escolas públicas estão expostos, os quais acabam refletindo no processo de formação destes cidadãos dentro do contexto escolar. 
Neste sentido, reflete-se que as principais preocupações dos docentes de escolas públicas se referem ao 'impacto' de suas ações, revelando que os professores estão cada vez mais preocupados com seus alunos no que se refere tanto à aprendizagem quanto aos aspectos sociais e emocionais (SHIGUNOV; FARIAS; NASCIMENTO, 2002). Informações similares às relatadas pelos professores em final de carreira foram disponibilizadas por professores americanos com maior tempo de intervenção profissional e que se aproximam da aposentadoria (MARSO; PIGGE, 1994), os quais reportam baixo nível de preocupação 'consigo próprio' e grande inquietação com o 'impacto' de suas posturas educativas e do cotidiano na vida dos alunos do que professores menos experientes.

Além da preocupação com o 'impacto', os colegas de profissão dos professores A e D evidenciaram que esses educadores ainda demonstram em suas ações determinada frustração no que diz respeito às condições de trabalho oferecidas aos educadores desta disciplina para desenvolverem suas ações docentes no magistério público estadual.

[...] até pela falta de material, de condições de trabalho que o Estado oferece para as escolas públicas. [...] não tem um ginásio de esportes e o material é de $5^{\mathrm{a}}$ categoria, nem de $2^{\mathrm{a}}$ é, material muito ruim para trabalhar (COLEGA DE PROFISSÃO A).

Eu acho que no geral o que ela mais anseia mesmo é por um material mais digno de trabalho, local digno de trabalho, isso ela reclama muito, ela sempre diz: 'como é que eu vou trabalhar com isso?' (COLEGA DE PROFISSÃO D).

\section{CONCLUSÕES}

As evidências encontradas no presente estudo revelaram que as preocupações de professores de Educação Física atuantes em escolas públicas se modificam com o avanço na carreira docente.

Os professores iniciaram na profissão preocupados com a 'tarefa' de ensinar, nomeadamente inquietos com os materiais e os espaços oferecidos para desenvolverem as ações pedagógicas planejadas. No decorrer dos anos de docência, essa preocupação com a 'tarefa' educativa foi intensificada. Contudo, os professores, por meio das experiências adquiridas no dia a dia da profissão, passaram da ênfase nas condições de trabalho proporcionadas pela escola para a ênfase na ação didática por eles desenvolvida, bem como nas propostas governamentais para a escola pública.

$\mathrm{Na}$ fase final de seus percursos profissionais, os docentes de Educação Física revelaram elevada inquietação com os problemas sociais dos alunos, demonstrando as mudanças ocorridas na evolução da percepção de preocupações por educadores que já atuaram durante anos no magistério público estadual. 
As diferenças encontradas entre os resultados obtidos nessa investigação e aqueles evidenciados na literatura consultada, bem como a escassez de estudos nacionais sobre a temática, permitem a recomendação de aprofundamento nas investigações que envolvam professores inseridos no contexto escolar e que se encontram em diferentes fases do ciclo de vida docente. Além disso, na tentativa de melhor esclarecer a evolução nas preocupações de professores de diferentes áreas, há a necessidade de utilizar nesses estudos diferentes instrumentos de coleta das informações, possibilitando assim a ampliação do conhecimento em torno do foco de estudo.

\section{Concerns along teacher's career: case studies with Physical Education teachers of public teaching statewide}

ABSTRACT: The aim of this study was to analyze the concerns of Physical Education teachers. The participants were four permanent teachers, with more than 25 years experience in public teaching in the state of Santa Catarina. Semi-structured interviews were conducted and the technique of content analysis was used in the information analysis. The results revealed major changes in pedagogical concerns along the teaching career. The teachers started in the career concerned with the offered working conditions, concerning themselves later into didactic action and government proposals for public schools. In the final cycles of teaching life, the concerns of social problems to which students are exposed were highlighted.

KEYWORDS: Teaching; concerns; public schools; physical education.

\section{Preocupaciones a lo largo de la carrera docente: estudios de caso con profesores de Educación Física de la enseñanza pública estadual}

RESUMEN: El objetivo de este estudio fue analizar las preocupaciones de los profesores de Educación Física. Los participantes fueron cuatro profesores efectivos con más de 25 años de experiencia en la enseñanza pública del estado de Santa Catarina. Entrevistas semiestructuradas se realizaron y la técnica de análisis de contenido fue utilizada para analizar las informaciones. Los resultados revelaron cambios importantes en las preocupaciones a lo largo de la carrera docente. Los maestros se iniciaron en la profesión preocupados con las condiciones de trabajo ofrecidas, guiándose después en la acción didáctica y en las propuestas del gobierno para las escuelas públicas. En los últimos ciclos de la vida docente, se destacaron las preocupaciones por los problemas sociales que los estudiantes están expuestos.

PALABRAS CLAVE: Docentes; preocupaciones; escuelas públicas; educación física.

\section{REFERÊNCIAS}

BARDIN, L. Análise de conteúdo. Rio de Janeiro: Edições 70, 1977.

BARONE, T. et al. A future for teacher education: developing a strong sense of professionalism. In: SIKULA, J.; BUTTEY, T. J.; GUYTON, E. Handbook of research on teacher education. New York: Macmillan, 1996. p. I I | 8- I 149. 
BOGDAN, R. C.; BIKLEN, S. A. Investigação qualitativa em educação: uma introdução à teoria e aos métodos. Porto: Porto Editora, 1994.

BOTH, J.; NASCIMENTO, J. V.; BORGATTO, A. F. Percepção da qualidade de vida no trabalho ao longo da carreira docente em Educação Física. Revista Brasileira de Cineantropometria e Desempenho Humano, Florianópolis, v. 10, n. 4, p. 372-378, 2008.

FARIAS, G. O. et al. Carreira docente em Educação Física: uma abordagem sobre a qualidade de vida no trabalho de professores da rede estadual de ensino do Rio Grande do Sul. Revista da Educação Física/UEM, Maringá, v. 19, n. I , p. I I-22, 2008a.

FARIAS, G. O. et al. Preocupações pedagógicas de estudantes-estagiários na formação inicial em Educação Física. Motriz, Rio Claro, v. I4, n. 3, p. 3 I0-319, jul./set. 2008b.

FOLLE, A. et al. Carreira no magistério público e nível de qualidade de vida no trabalho docente em Educação Física. Motriz, Rio Claro, v. I4, n. 3, p. 210-2 I2, jul./set. 2008.

FOLLE, A. et al. Construção da carreira docente em Educação Física: escolhas, trajetórias e perspectivas. Movimento, Porto Alegre, v. I 5, p. 25-49, jan./mar. 2009.

FOLLE, A.; NASCIMENTO, J. V. Momentos marcantes da trajetória docente em Educação Física. Motriz, Rio Claro, v. I5, n. I, p. 92-103, jan./mar. 2009.

FULLER, F. F. Concerns of teachers: a developmental conceptualization. American Education Research Journal, Washington, v. 6, n. 2, p. 207-226, mar. 1969.

.; CASE, C. Concerns of teacher: a manual for teacher educator. Increase teacher satisfaction with professional preparation by considering teacher's concerns when planning preservice and inservice education. Washington: DHEW, 1969.

HOLLY, M. L. Investigando a vida profissional dos professores: diários biográficos. In: NÓVOA, A. Vidas de professores. 2. ed. Porto: Porto Editora, 2000. p. 79- I 10.

HOPF, A. C. O.; CANFIELD, M. S. Profissão docente: estudo da trajetória de professores universitários de Educação Física. Kinesis, Santa Maria, n. 24, p. 49-7I, 2001.

HUBERMAN, M. O ciclo de vida profissional dos professores. In: NÓvOA, A. Vidas de professores. 2. ed. Porto: Porto Editora, 2000. p. 31-62.

LEMOS, C. A. F.; NASCIMENTO, J. V.; BORGATTO, A. F. Parâmetros individuas e sócioambientais da qualidade de vida percebida na carreira docente em Educação Física. Revista Brasileira de Educação Física e Esportes, São Paulo, v. 2 I, n. 2, p. 81-93, abr./jun. 2007.

MARSO, R. N.; PIGGE, F. L. Outstanding teachers' concerns about teaching at four stages of career development. In: ANNUAL MEETING OF THE AMERICAN EDUCATION RESEARCH ASSOCIATION, 6I., 1994, New Orleans. Anais... New Orleans: AERA, 1994. p. $|-| \mid$. 
MATOS, Z. et al. A valorização dos problemas em situação de estágio: preocupações dos estudantes-estagiários e formadores. In: BENTO, J.; MARQUES, A. As ciências do desporto na escola. Porto: FCDEF, 1991. p. 359-367.

MCBRIDE, R. E. Perceived teaching and program concerns among pre-service teachers, university supervisors, and cooperating teachers. Journal of Teaching in Physical Education, Champaign, v. 3, n. 3, p. 36-43, apr. 1984.

MOLINA, R. M. K. O enfoque teórico metodológico qualitativo e o estudo de caso: uma reflexão introdutória. In: MOLINA NETO, V.; TRIVIÑOS, A. N. S. A pesquisa qualitativa na Educação Física: alternativas metodológicas. Porto Alegre: Sulina, 2004. p. 95- 105.

NASCIMENTO, J. V.; GRAÇA, A. A evolução da percepção de competência profissional de professores de Educação Física ao longo da carreira docente. In: CONGRESSO DE EDUCAÇÃO FÍSICA E CIÊNCIAS DO DESPORTO DOS PAÍSES DE LÍNGUA PORTUGUESA, 6., 1998, La Coruña. Actas... La Coruña: INEF, I998. p. 320-335.

OLSEN, D. G.; HEYSE, K. L. Development and concerns of first-year and reentry teachers with and without mentors. In: ANNUAL MEETING OF THE AMERICAN EDUCATION RESEARCH ASSOCIATION, 57., 1990, Boston. Anais... Boston: AERA, 1990. p. I-24.

OSLER, A. Teachers' biographies and educational development: a Kenyan case study. International Journal of Educational Development, Bridgetown, v. 17, n. 4, p. 36I-37I, oct. 1997.

SHIGUNOV, V.; FARIAS, G. O.; NASCIMENTO, J. V. O percurso profissional dos professores de Educação Física nas escolas. In: SHIGUNOV, V.; SHIGUNOV NETO, A. Educação Física: conhecimento teórico x prática pedagógica. Porto Alegre: Mediação, 2002. p. I03- 152.

SILVA, M. C. M. O primeiro ano de docência: o choque com a realidade. In: ESTRELA, M. T. Viver e construir a profissão docente. Porto: Porto Editora, 1997. p. 53-80.

STEFY, B. E. et al. The model and its application. In: STEFY, B. E. et al. Life cycle of the career teacher. California: Kappa Delta Pi, 2000. p. 01-25.

STROOT, S. Organizational socialization: factors impacting beginning teachers. In: SILVERMAN, S. J.; ENNIS, C. Student learning in physical education. Champaign: Human Kinetics, 1996. p. 339-365.

WENDT, J. C.; BAIN, L. L.; JACKSON, A. S. Fuller's concerns theory as tested on prospective Physical Education. Journal of Teaching in Physical Education, Champaign, v. I, n. 0 , p. 66-70, apr. 1981.

ZIELINSKI, E. J.; PRESTON, D. D. A evolution of preservice science teachers' concerns about teaching. ANNUAL MEETING OF THE NATIONAL ASSOCIATION OF RESEARCH IN SCIENCE TEACHING, 59., 1992, Boston. Anais... Boston: AERA, 1992. p. 1-20. 
Recebido: 20 maio 2010

Aprovado: II jan. 20 I I

Endereço para correspondência:

Alexandra Folle

Rua José Victor da Rosa, 722, apto I05A

Bairro Barreiros

São José-SC

CEP: $88040-600$ 